\title{
锌胁迫下甘蓝型油菜发芽期下胚轴长的全基因组关联分析
}

魏丽娟 $^{* *}$ 申树林 ${ }^{* *}$ 黄小虎 马国强王曦䑣 杨怡玲 李洹东 王书贤
朱美晨 唐章林 卢坤 李加纳 ${ }^{*}$ 曲存民

西南大学农学与生物科技学院 / 油菜工程研究中心 / 西南大学现代农业科学研究院, 重庆 400715

摘 要: 锌 $(\mathrm{Zn})$ 是重要的微量元素之一, 但土壤中过量的锌累积会影响植物的生长发育。本研究以不同遗传来源的 140 份甘蓝型油菜为材料, 利用芸薹属 $60 \mathrm{~K} \mathrm{SNP}$ 芯片对锌胁迫下 $\left(30 \mathrm{mg} \mathrm{L}^{-1}\right)$ 甘蓝型油菜发芽期相对下胚轴长(RHL)进 行全基因组关联分析, 筛选与甘蓝型油菜发芽期下胚轴长度显著关联的 SNP 位点及候选基因。群体结构分析表明, 供试的 140 份甘蓝型油菜被分为 2 个亚群, 其中 $89 \%$ 材料间亲缘关系小于 0.1 , 说明供试群体材料亲缘关系比较远。 GWAS 分析共检测到 8 个与 RHL 显著关联的 SNP 位点, 单个 SNP 位点分别可解释 $22.0 \%$ 33.2\%的表型变异。转录 组分析获得的差异基因 GO 富集分析结果表明, 上调表达基因主要参与氧化还原反应、离子转运、胁迫反应、防御 反应和硫化合物转运。综合全基因组关联分析和转录组测序结果, 共鉴定到 19 个与锌胁迫相关的候选基因, 包括编 码锌指蛋白家族成员(B-box 型和 ZFP1)、谷胱甘肽转移酶 GSTU21、过氧化物酶家族蛋白、ABC 和 MFS 转运蛋白及 细胞壁相关激酶蛋白和一些重要的转录因子(BnaA07g27330D、BnaA02g30270D、BnaA07g27840D、BnaA07g31860D 和 BnaA07g28000), 为深入解析油菜锌胁迫分子机制提供了参考。

关键词：甘蓝型油菜；重金属；锌胁迫；全基因组关联分析；发芽期

\section{Genome-wide association analysis reveals zinc-tolerant loci of rapeseed at germination stage}

WEI Li-Juan ${ }^{* *}$, SHEN Shu-Lin ${ }^{* *}$, HUANG Xiao-Hu, MA Guo-Qiang, WANG Xi-Tong, YANG Yi-Ling, LI Huan-Dong, WANG Shu-Xian, ZHU Mei-Chen, TANG Zhang-Lin, LU Kun, LI Jia-Na*, and QU Cun-Min

College of Agronomy and Biotechnology, Southwest University / Chongqing Engineering Research Center for Rapeseed / Academy of Agricultural Sciences, Southwest University, Chongqing 400715, China

\begin{abstract}
Zinc $(\mathrm{Zn})$ is one of the important mircroelements, but the excessive amount application would affect plant growth and development. Genome-wide association analysis (GWAS) was performed on the relative hypocotyl length (RHL) using the 140 . napus genotyped under zinc stress treatment $\left(30 \mathrm{mg} \mathrm{L}^{-1}\right)$ at germination stage by Illumina $60 \mathrm{~K}$ SNP array, and then significant SNP locus and candidate genes were detected. In the study, the population structure analysis revealed that the 140 B. napus were classified into two subgroups, and the kinship coefficients of the $89 \%$ materials were less than 0.1 , indicating the tested population had a distant relationship. GWAS analysis indicated that there were significantly 8 SNP locus correlated to RHL, and single SNP loci could give an explanation on the $22.0 \%-33.2 \%$ phenotype variation. The differential expressed gene (DEGs) were detected by
\end{abstract}

\footnotetext{
本研究由国家自然科学基金项目(31701460), 中央高校基本科研业务费(XDJK2019C041, XDJK2020D023), 重庆市基础科学与创新研 究项目(cstc2016shms-ztzx80010, cstc2017jcyjAX0321), 国家现代农业产业技术体系建设专项(CARS-12)和高等学校学科创新引智基地 111 项目(B12006)资助。

This study was supported by the National Natural Science Foundation of China (31701460), the Fundamental Research Funds for the Central Universities (XDJK2019C041, XDJK2020D023), the Chongqing Basic Scientific and Advanced Technology Research (cstc2016shmsztzx80010, cstc2017jcyjAX0321), the China Agricultural Research System (CARS-12), and the Project of Intellectual Base for Discipline Innovation in Colleges and Universities (B12006).

*通信作者(Corresponding authors): 李加纳, E-mail: 1jn1950@swu.edu.cn, Tel: 023-68250701; 曲存民, E-mail: drqucunmin@swu.edu.cn, Tel: 023-68250701

** 同等贡献(Contributed equally to this work)

第一作者联系方式: 魏丽娟, E-mail: lijuan525888@163.com

Received (收稿日期): 2020-02-18; Accepted (接受日期): 2020-04-15; Published online (网络出版日期): 2020-05-08.

URL: http://kns.cnki.net/kcms/detail/11.1809.S.20200507.1507.005.html
} 
RNA-Seq. GO enrichment analysis indicated that the up-regulated genes mainly participated in redox reaction, ion transport, stress response, defense response and sulfur compound transport. Nineteen candidate genes response to zinc stress were identified by GWAS analysis and RNA-seq, including the genes encoding zinc finger protein (B-box type and ZFP1), glutathione transferase GSTU21, peroxidase family protein, $\mathrm{ABC}$ and MFS transporters, cell wall-related kinase protein, and genes encoding transcription factors (TF), such as BnaA07g27330D (MYB), BnaA02g30270D (bHLH), BnaA07g27840D (WRKY57), BnaA07g31860D (ORA47), and BnaA07g28000 (NAC). This study laid the foundation for understanding the molecular mechanism of zinc stress in B. napus.

Keywords: Brassica napus; heavy metal; zinc stress; GWAS; germination stage

近年来，土壤重金属污染问题愈发严重，对人 类身体健康和生态系统产生重大影响 ${ }^{[1]}$ 。锌是植物 生长发育所必需的微量元素之一, 适量锌可促进植 物生长发育, 增强植物对不良环境的适应性 ${ }^{[2-3]}$ 。然 而过度使用不仅会造成严重的环境污染，还会降低 土壤微生物的活性, 减缓土壤有机质的分解, 进而 影响植物根的生长和光合作用 ${ }^{[4-6]}$ 。油菜被认为是 修复重金属(如 $\mathrm{Cu} 、 \mathrm{Cd} 、 \mathrm{Zn}$ )污染土壤的理想植物之

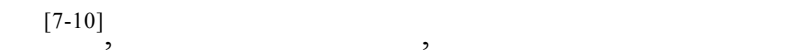
高的生物产量 ${ }^{[7,11]}$ 。曹春信等 ${ }^{[12]}$ 通过研究油菜地上部 器官对锌富集的特征发现, 锌在茎秆中的含量大于 籽粒。挖掘耐锌性关键位点和候选基因对耐锌性油 菜品种的培育具有重要意义, 全基因组关联分析被 广泛应用于作物重金属抗性位点的检测。Zhang 等 ${ }^{[13]}$ 利用全基因组关联分析方法, 在水稻中共检测到 31 个耐锌 QTL 位点。Chen 等 ${ }^{[14]}$ 利用 Brassica Illumina $60 \mathrm{~K} \mathrm{SNP}$ 芯片进行全基因组关联分析, 检测出 25 个 甘蓝型油菜耐镉 QTL 位点, 并找到 NRAMP6、IRT1、 $C A D 1$ 和 PCS2 四个候选基因。Zhang 等 ${ }^{[15]}$ 检测到 4 个甘蓝型油菜耐镉位点, 并鉴定出一些候选基因, 如 HIPP27、EXPB4、EMB1793 和 $C D S P 3$ 。曲存民 等 ${ }^{[16]}$ 检测到 70 个甘蓝型油菜耐砷性的显著关联位 点, 并篮选出 PHT3;3 和 PHT 1;9 等与甘蓝型油菜砷 离子吸收转运相关的候选基因。超富集植物对重金 属的积累和耐性机制研究也取得了一定进展, 许多 蛋白参与锌的吸收、转运和咜存, 包括 CDF (Cation Diffusion Facilitator)蛋白家族 ${ }^{[17]}$ 、NRAMP 蛋白家 族 ${ }^{[18]} 、 Z I P$ 蛋白家族 ${ }^{[19]}$ 、HMA 蛋白家族(P-type ATPases) ${ }^{[20]} 、 Y S L$ (yellow stripe-like)蛋白家族 ${ }^{[21]} 、$

ABC (ATP-binding cassette)转运蛋白家族 ${ }^{[2,22]}$ 。但关 于甘蓝型油菜耐锌性 QTL 定位和候选基因鉴定并未 见相关报道。

为挖掘甘蓝型油菜与耐锌性状相关联的关键位 点及候选基因, 本研究采用 GWAS 方法获得与下胚 轴长显著关联的 SNP 标记, 结合转录组数据获得锌 胁迫前后差异表达基因, 进一步确定影响下胚轴长
的关键候选基因。本研究不仅为甘蓝型油菜耐锌性 种质资源的鉴定提供分子标记, 而且可以为耐锌性 油菜资源利用和新品种培育提供理论依据。

\section{1 材料与方法}

\section{1 试验材料}

供试材料为国内外收集的甘蓝型油菜自交系品 种 140 份, 其中国内材料 123 份, 主要来自重庆、四 川、湖北、湖南等地, 其余 17 份材料来自加拿大和 德国等国家, 所有材料由西南大学重庆市油菜工程 技术研究中心收集并提供。

\section{2 试验处理与性状分析}

从 140 份研究材料中随机抽取 10 份材料(附表 $1)$, 分别用 $0 、 5 、 10 、 15 、 20 、 30$ 和 $50 \mathrm{mg} \mathrm{L}^{-1}$ 浓度 的 $\mathrm{Zn}\left(\mathrm{NO}_{3}\right)_{2}$ 进行处理, 比较分析发现, 处理浓度为 $30 \mathrm{mg} \mathrm{L}^{-1}$ 时材料间长势差异较大, 确定为最佳处理 浓度(表 1)。试验分为对照组和处理组, 重复 3 次, 挑 选大小均匀、饱满的种子各 100 粒, 分别播种于对 照纯水和 $30 \mathrm{mg} \mathrm{L}^{-1}$ 的 $\mathrm{Zn}\left(\mathrm{NO}_{3}\right)_{2}$ 溶液处理的培养盘 (长 $37.0 \mathrm{~cm} \times$ 宽 $24.5 \mathrm{~cm} \times$ 高 $6.5 \mathrm{~cm}$, 体积为 $4.5 \mathrm{~L}$ ), 覆盖保鲜膜。生长条件为昼夜温度为 $25^{\circ} \mathrm{C}$, 光照/黑 暗时间为 $16 \mathrm{~h} / 8 \mathrm{~h}$, 光照强度为 $100 \mu \mathrm{mol} \mathrm{m} \mathrm{m}^{-2} \mathrm{~s}^{-1}$, 相 对湿度为 $60 \%$ 。墦种 $7 \mathrm{~d}$ 后, 选取长势一致的 5 株幼苗, 分别测量对照和锌胁迫下的下胚轴长 (hypocotyl length, HL)。将处理和对照的相对值作 为衡量锌胁迫对甘蓝型油菜生长的影响 ${ }^{[24]}$, 记为 相对下胚轴长(relative hypocotyl length, RHL)。计 算公式：相对性状值 $(\%)=$ 处理组测定值/对照组测 定值 $\times 100 \%{ }^{[16]}$ 。利用 Microsoft Excel 2013 绘制正态 分布图, 利用 SPSS 统计分析软件进行偏度和峰度 分析。

\section{3 基因型分析及 SNP 标记定位}

利用芸薹属 $60 \mathrm{~K}$ SNP 芯片, 参照 $\mathrm{Qu}$ 等 ${ }^{[25-26]}$ 方 法, 对 140 份材料进行基因型分析, 去掉最小基因 型频率(minor allele frequency, MAF)低于 0.05 和 SNP 得率(call frequency)小于 $80 \%$ 的标记。为确定 
SNP 在染色体上的位置, 利用探针序列与基因组进 行 BLASTN 比对, E-value 设定为 $1 \mathrm{e}^{-5}$ 。去掉 Bit-Score 相同的 SNP，最终获得 30,288 个 SNP 标记用于群体 性状的关联分析。

\section{4 群体结构分析与亲缘关系}

利用 STRUCTURE 软件进行甘蓝型油菜群体结 构分析 ${ }^{[27]}$, 组群数目 $(K)$ 设定为 $1 \sim 10, K$ 值运行 5 次 (number of iterations), 将 MCMC (Markov Chain Monte Carlo)不作数迭代(length of burn-in period)和 不作数迭代后的 MCMC 全部设为 100,000 次, 在混 合模型下进行运算。最后用运算得到的后验概率值 和 2 个连续的后验概率值的变化速率 $(\Delta K)$ 来确定群 体中存在的亚群数目 ${ }^{[28]}$ 。利用 SPAGeDi v1.4 软件进 行亲缘关系(relative kinship)分析，并计算亲缘关系 的矩阵 ${ }^{[29]}$ 。

\section{5 全基因组关联分析及候选基因鉴定}

利用 TASSEL 5.0 软件 ${ }^{[30]}$ 中的一般线性模型 (General Linear Model, GLM)和混合线性模型(Mixed Linear Model, MLM), 结合 SNP 芯片基因型数据, 以 $Q$ 值和亲缘关系 $K$ 值作为协变量, 进行全基因组 关联分析, 确定关联位点和标记对表型变异的解释 率 $\left(R^{2}\right)$ 。本研究采用了 6 种模型进行关联分析，包括 GLM 中的 naive、 $Q$ 和 PCA 模型, MLM 中的 $K 、 Q+K$ 和 $\mathrm{PCA}+K$ 模型。根据每个 SNP 位点的 $-\log _{10}(P)$ 观 察值和期望值, 利用 $\mathrm{R}$ 软件(https://www.r-project. org/)绘制 Quantile-Quantile 散点图(QQ plot)。曼哈顿
图(Manhattan plot)利用 $\mathrm{R}$ 语言程序包的 mrMLM (Multi-Locus Random-SNP-Effect Mixed Linear Model)进行绘制 ${ }^{[31]}$ 。与性状显著关联的 SNP 位点的 阈值为 $P<3.30 \times 10^{-5}$, 计算方法为: $1 / N(N=$ $30,288)^{[16]}$ 。利用 TASSEL 5.0 软件 ${ }^{[30]}$ 计算 linkage disequilibrium (LD)在油菜不同染色上的分布情况, 确定不同染色体的 LD 衰减距离, 根据 LD 确定候选 基因区间。

\section{6 甘蓝型油菜锌胁迫转录组测序}

取甘蓝型油菜自交系 07191 锌胁迫处理前和处 理 $7 \mathrm{~d}$ 后的幼苗，于液氮中保存，参照曲存民等 ${ }^{[16]}$ 方法提取总 RNA，利用 Illumina Hiseq 2500 进行转 录组测序, 以甘蓝型油菜为参考基因组 ${ }^{[32]}$, 利用 Cuffdiff 篮选差异表达基因，篮选标准为 FDR $<0.01$, $\log _{2} \mid$ (fold change) $\mid>1$ 。 上调和下调的差异表达基因 $\mathrm{GO}$ 富集分析采用基迪奥云平台进行分析 (https://www.omicshare.com/)。

\section{2 结果与分析}

2.1 甘蓝型油菜发芽期锌胁迫最佳浓度确定

为了确定油菜发芽期锌胁迫的最佳处理浓度, 本研究随机挑选 10 个材料, 分别利用不同浓度的 $\mathrm{Zn}\left(\mathrm{NO}_{3}\right)_{2}$ 溶液和纯水为对照进行处理, 发现处理浓 度为 $30 \mathrm{mg} \mathrm{L}^{-1}$ 时, 这些材料下胚轴长度明显受到抑 制, 且材料间变异较大(表 1)。因此，在发芽期筛选 耐锌油菜的最佳浓度为 $30 \mathrm{mg} \mathrm{L}^{-1}$ 。

表 1 不同 $\mathrm{Zn}\left(\mathrm{NO}_{3}\right)_{2}$ 溶液浓度下油菜下胚轴长度

Table 1 Hypocotyl length with different $\mathrm{Zn}\left(\mathrm{NO}_{3}\right)_{2}$ concentration solutions in $B$. napus

\begin{tabular}{|c|c|c|c|c|c|c|c|c|}
\hline \multirow{2}{*}{$\begin{array}{c}\text { 品种 } \\
\text { Accessions }\end{array}$} & \multicolumn{8}{|c|}{$\mathrm{Zn}\left(\mathrm{NO}_{3}\right)_{2}$ 溶液浓度 Concentration of $\mathrm{Zn}\left(\mathrm{NO}_{3}\right)_{2}$ solutions $\left(\mathrm{mg} \mathrm{L}^{-1}\right)$} \\
\hline & 0 & 5 & 10 & 15 & 20 & 30 & 50 & 70 \\
\hline 1 & 5.76 & 4.46 & 4.74 & 5.82 & 3.78 & 2.54 & 2.54 & 1.68 \\
\hline 2 & 4.38 & 4.38 & 4.02 & 3.16 & 2.38 & 2.54 & 2.52 & 2.08 \\
\hline 3 & 6.80 & 6.64 & 5.02 & 6.02 & 4.34 & 2.62 & 2.24 & 2.34 \\
\hline 4 & 7.60 & 7.66 & 6.64 & 5.20 & 4.20 & 3.14 & 2.76 & 2.14 \\
\hline 5 & 6.70 & 6.28 & 5.24 & 4.32 & 3.24 & 3.20 & 2.84 & 1.80 \\
\hline 6 & 6.25 & 5.88 & 5.13 & 4.90 & 3.59 & 2.81 & 2.58 & 2.01 \\
\hline 7 & 7.90 & 6.30 & 8.40 & 6.52 & 5.88 & 5.46 & 4.84 & 2.60 \\
\hline 8 & 5.90 & 7.98 & 8.64 & 4.50 & 4.08 & 4.58 & 4.64 & 2.40 \\
\hline 9 & 6.30 & 7.90 & 7.10 & 5.60 & 6.54 & 4.50 & 3.74 & 2.40 \\
\hline 10 & 6.96 & 7.08 & 8.06 & 5.73 & 6.01 & 4.86 & 4.94 & 2.91 \\
\hline 平均值 Mean (cm) & 6.45 & 6.46 & 6.30 & 3.78 & 3.58 & 2.48 & 3.36 & 2.24 \\
\hline 标准差 SD (cm) & 1.00 & 1.29 & 1.68 & 1.17 & 1.25 & 0.87 & 1.07 & 0.37 \\
\hline 变异系数 CV $(\%)$ & 0.155 & 0.200 & 0.267 & 0.309 & 0.349 & 0.352 & 0.319 & 0.166 \\
\hline
\end{tabular}




\section{2 甘蓝型油菜锌胁迫性状表型变异分析}

对 140 份油菜正常和锌胁迫条件下的下胚轴长 度进行统计发现, 在正常条件下, 甘蓝型油菜下胚 轴长度为 $3.66 \sim 7.99 \mathrm{~cm}$, 变异系数为 $15.8 \%$; 锌胁 迫下, 下胚轴长度为 $2.28 \sim 6.47 \mathrm{~cm}$, 变异系数为 $18.8 \%$; 相对下胚轴长的变异范围为 $0.38 \sim 1.08$, 均 值为 0.73 , 变异系数为 $17.6 \%$, 表现出广泛的表型
变异(表 2)。锌胁迫下，大部分材料的下胚轴长度都 较正常生长状态的下胚轴短, 只有 5 个半冬性材料 例外(甘油 5 号、SWU94、中油 821、川油 18 和 $\mathrm{Wx} 10213)$, 表明 $30 \mathrm{mg} \mathrm{L}{ }^{-1}$ 锌胁迫严重抑制了甘蓝 型油菜下胚轴伸长。相对下胚轴长呈连续性正态分 布, 说明其受多基因控制, 表型为典型的数量性状 遗传特点(图 1)。

表 2 锌胁迫下甘蓝型油菜发芽期性状统计分析

Table 2 Statistical analysis of the traits at germination stage under zinc stress

\begin{tabular}{|c|c|c|c|c|c|c|}
\hline 性状 & 最小值 & 最大值 & 均值 \pm 标准差 & 变异系数 & 偏度 & 峰度 \\
\hline Trait & Min. $(\mathrm{cm})$ & Max.(cm) & Mean \pm SD & CV (\%) & Skewness & Kurtosis \\
\hline $\mathrm{CHL}$ & 3.66 & 7.99 & $5.77 \pm 0.92$ & 15.85 & -0.13 & 0.83 \\
\hline THL & 2.28 & 6.47 & $4.24 \pm 0.80$ & 18.84 & 0.41 & 0.02 \\
\hline RHL & 0.38 & 1.08 & $0.73 \pm 0.13$ & 17.57 & 0.28 & 0.15 \\
\hline
\end{tabular}

CHL: 正常条件下的下胚轴长; THL: 锌胁迫下的下胚轴长; RHL: 正常与锌胁迫下相对下胚轴长。

CHL: the hypocotyl length under normal condition; THL: the hypocotyl length under zinc stress; RHL: the relative hypocotyl length under normal and zinc stress treatments.

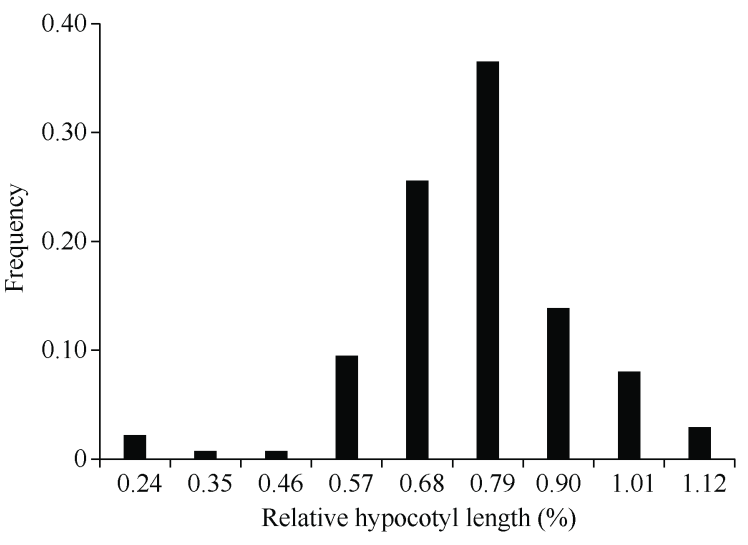

图 1 锌胁迫下甘蓝型油菜相对下胚轴长频率分布图

Fig. 1 Frequency distribution of RHL under zinc stress in $B$. napus

\section{3 群体结构和亲缘关系分析}

利用 30,288 个 SNP 标记进行关联群体的群体结 构和亲缘关系分析, 当 $K=2$ 时, $\Delta K$ 值最大(图 2-A), 因此, 该群体的亚群数为 2 , 生成的最优群体结构的 $\mathrm{Q}$ 矩阵见图 2-B。1 40 份甘蓝型材料中，89\%材料间 亲缘关系小于 0.1 (图 2-C), 表明该群体内材料间的 亲缘关系较远。

\section{4 耐锌胁迫下相对下胚轴长度的全基因组关 联分析}

对相对下胚轴长度的 QQ 图进行分析(图 3), 结 果表明, $\mathrm{K}+\mathrm{Q}$ 模型检测到的标记的 $P$ 值较其他模型 更接近期望值，其降低了假阳性，关联分析结果更 可靠。全基因组关联分析共检测到 8 个显著关联的
A

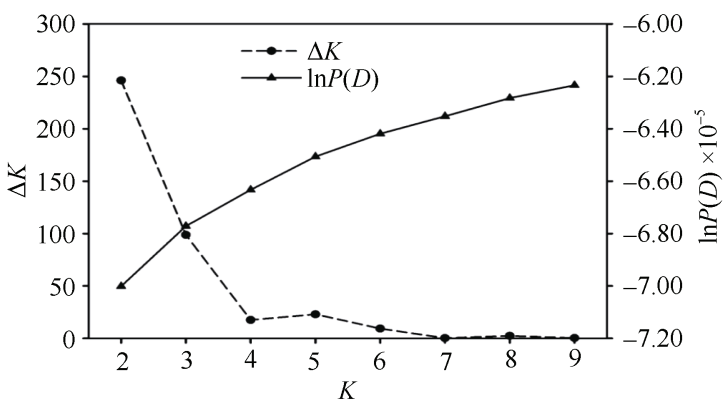

B
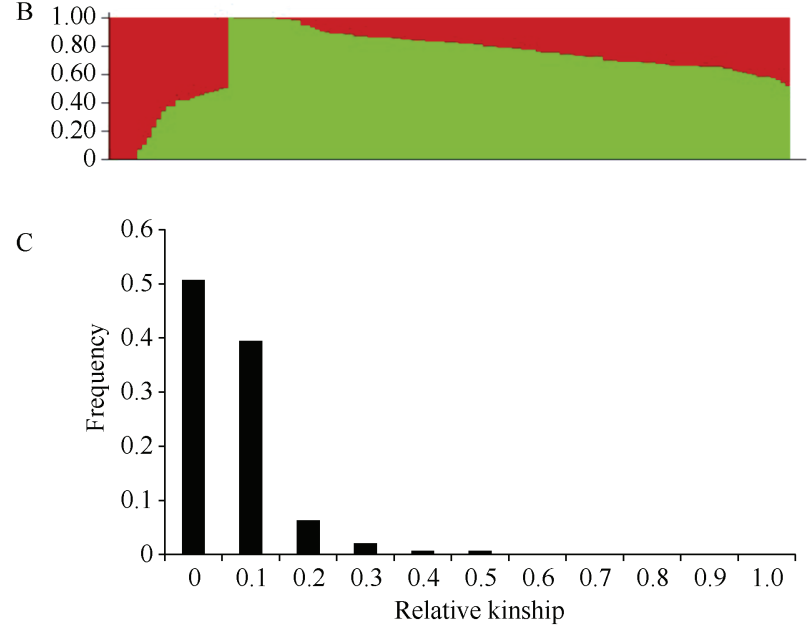

图 2 基于 SNP 标记估算群体结构关系图和亲缘关系图

Fig. 2 Population structure and relative kinship diagram based on SNP markers

A: $\ln P(D)$ 和 $\Delta K$ 变化关系图; B: $K=2$ 时群体结构图; C: 140 份甘 蓝型油菜亲缘关系图。

A: plot of $\ln P(D)$ and $\Delta K$; B: population structure profile $(K=2)$, the areas of the two colors (green and red) indicate the proportion of each subgroup, respectively; C: relative kinship diagram of 140 B. napus. 
SNP 位点(图 3 和表 3), 分别位于 A02、A07、C04 和 $\mathrm{C} 06$ 染色体上, 单个 SNP 解释的表型变异为 $22.0 \% \sim 33.2 \%$ 。为了确定显著关联 SNP 位点的候选 基因区间，本研究对这些关联位点的染色体进行 LD 分析，利用 $R^{2}$ 值估计 $\mathrm{LD}, \mathrm{A} 02$ 和 $\mathrm{A} 07$ 染色体的衰减
距离为 $300 \mathrm{~kb}, \mathrm{C} 04$ 染色体衰减距离为 $700 \mathrm{~kb}, \mathrm{C} 06$ 染色体的衰减距离为 $1 \mathrm{Mb}$ (图 4-A)。另外, A07 染色体 上 $22.2 \mathrm{Mb} \sim 23.9 \mathrm{Mb}$ 与 $\mathrm{C} 06$ 染色体 $34.9 \mathrm{Mb} 37.2 \mathrm{Mb}$ 位于共线性区间内(图 4-B), 说明找到的显著关联的 SNP 位点位于这 2 个共线性区间内。

表 3 锌胁迫下甘蓝型油菜发芽期相对下胚轴长显著关联的 SNP 位点

Table 3 Significant SNP locus associated with the relative hypocotyl length at germination stage under zinc stress in $B$. napus

\begin{tabular}{ccccc}
\hline 染色体 & $\begin{array}{c}\text { 位置 } \\
\text { Chr. }\end{array}$ & $\begin{array}{c}P \text { 值 } \\
P \text {-value }\end{array}$ & $\begin{array}{c}\text { 显著性 } \\
\text { 贡献率 } \\
R^{2}(\%)\end{array}$ \\
\hline A02 & $22,075,111$ & $2.97 \mathrm{E}-06$ & 5.53 & 24.62 \\
A07 & $20,094,111$ & $3.97 \mathrm{E}-06$ & 5.40 & 22.11 \\
A07 & $22,001,673$ & $3.49 \mathrm{E}-06$ & 5.46 & 21.99 \\
A07 & $23,402,490$ & $7.70 \mathrm{E}-06$ & 5.11 & 19.90 \\
A07 & $23,555,825$ & $2.92 \mathrm{E}-06$ & 5.53 & 22.06 \\
A07 & $23,580,640$ & $7.50 \mathrm{E}-08$ & 7.13 & 33.18 \\
C04 & $4,456,230$ & $3.12 \mathrm{E}-06$ & 5.51 & 24.66 \\
C06 & $36,835,784$ & $2.55 \mathrm{E}-06$ & 5.59 & 24.45 \\
\hline
\end{tabular}

A

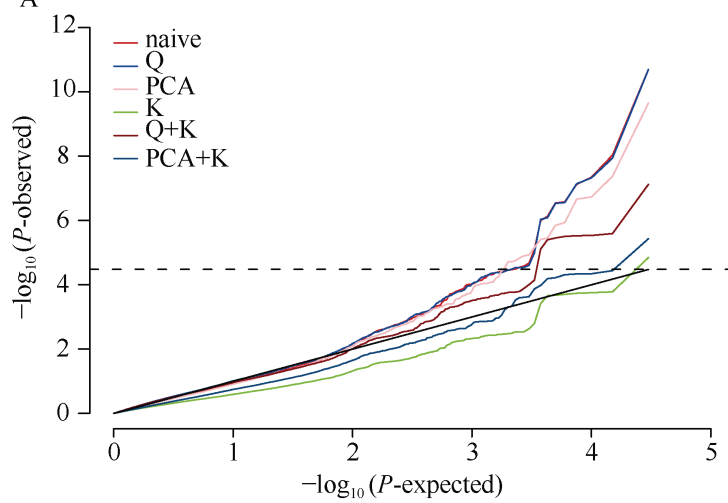

B

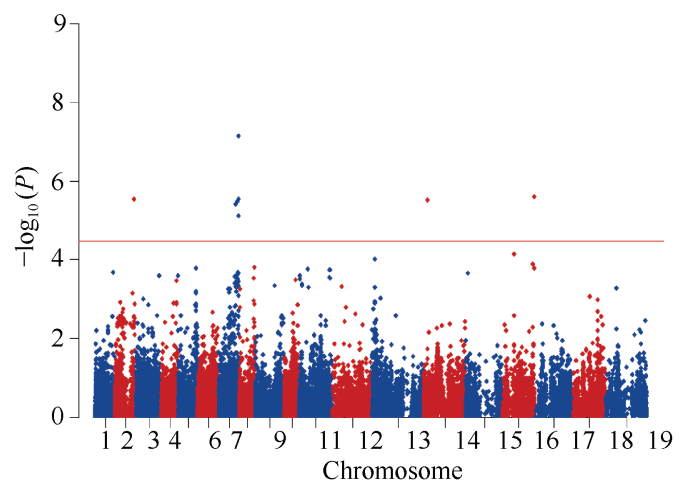

图 3 锌胁迫下甘蓝型油菜相对下胚轴长 $\mathbf{Q Q}$ 图和曼哈顿图

Fig. 3 QQ and Manhattan plots on RHL under zinc stress treatment in B. napus

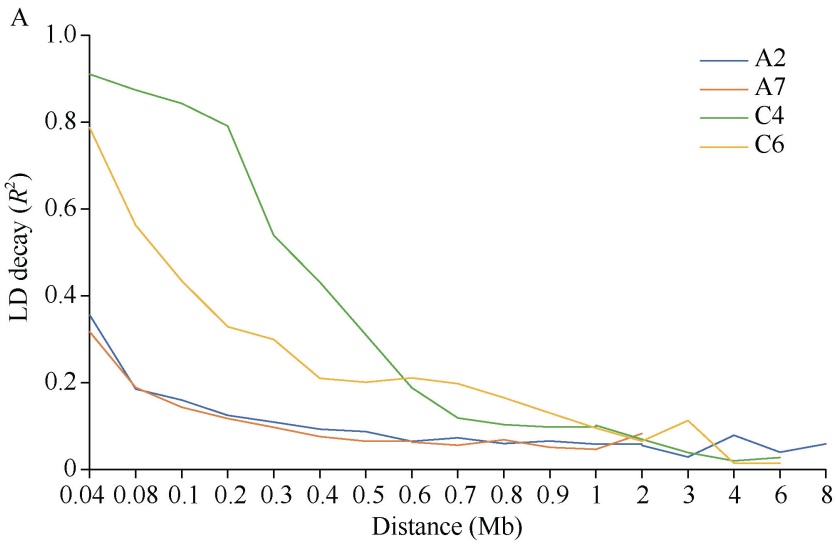

B

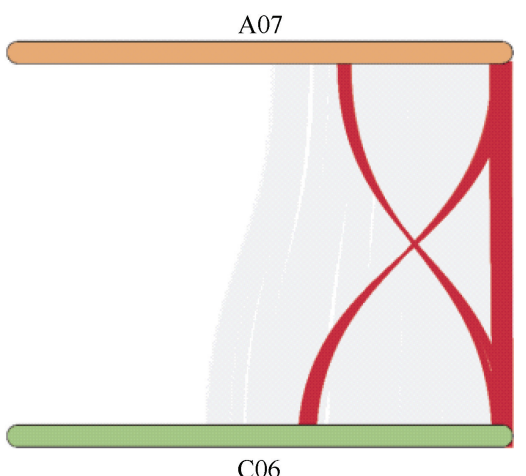

图 4 甘蓝型油菜染色体不同物理距离的 LD 分布(A)和共线性分析(B)

Fig. 4 LD distribution (A) and synteny analysis (B) in different distances in B. napus 


\section{5 锌胁迫下油菜幼苗差异表达基因}

转录组分析结果表明, 锌处理油菜幼苗 $7 \mathrm{~d}$ 后, 与对照相比, 上调基因 2733 个, 下调基因 3652 个, 其中差异转录因子/基因 616 个, 主要包括 $\mathrm{bHLH}$ (77)、ERF (73)、NAC (65)、MYB (60)、WRKY (55) 和 $\mathrm{C} 2 \mathrm{H} 2$ (33)家族(图 5)。ERF、NAC 和 WRKY 家族 基因上调数目较多, 而 bHLH、MYB 和 $\mathrm{C} 2 \mathrm{H} 2$ 家族 基因下调基因数目较多。本研究对上调和下调基因 分别进行 GO 功能富集分析, 上调基因主要富集在 细胞外区域和细胞膜, 分子功能是硫酸盐跨膜转运 功能, 主要参与氧化还原反应、离子转运、胁迫反 应、防御反应和硫化合物转运(图 6-A)。下调基因主 要富集在细胞外区域、质外体和细胞膜区域，主要 的分子功能是抗氧化活性和过氧化物酶活性, 主要 参与抗氧化反应、氧化还原反应和细胞壁生物合成 (图 6-B)。

\subsection{GWAS 与转录组结合鉴定共有基因}

根据各染色体的 LD 确定候选区间，参照油菜 基因组注释信息 ${ }^{[32]}$ ，共找到 19 个与锌胁迫相关的 候选基因(表 4), 这些基因主要包括编码锌指蛋白 家族成员 (B-box 型和 ZFP1)、谷胱甘肽转移酶 GSTU21、过氧化物酶家族蛋白、ABC 和 MFS 转 运蛋白及细胞壁相关激酶蛋白，并找到一些重要的 转录因子, 如 MYB、bHLH、NAC、ERF 和 WRKY, 大部分基因(除 GSTU21、ZFP1)。

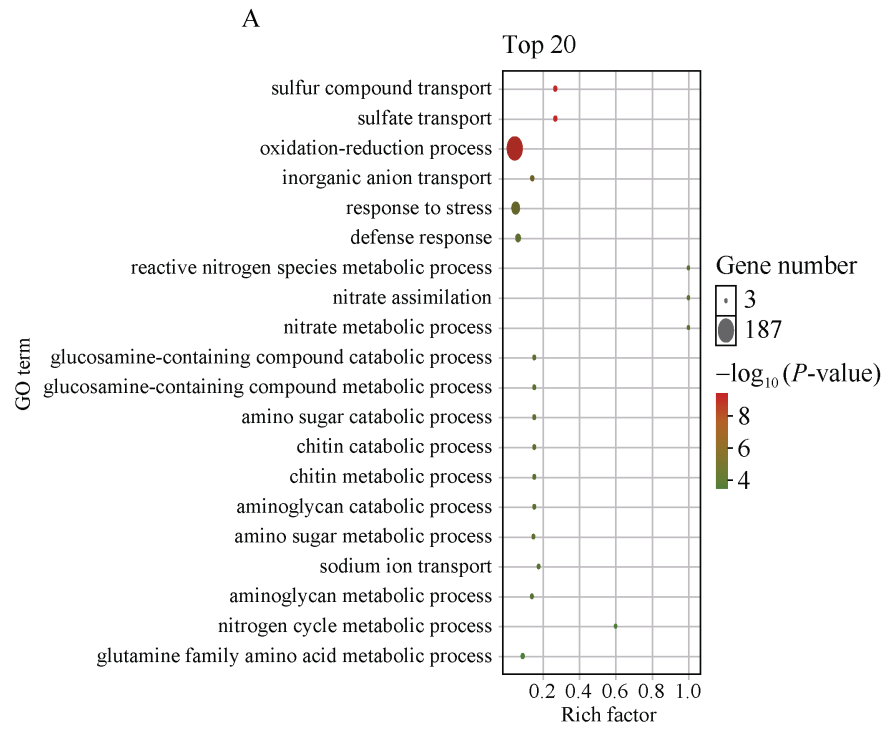

3 讨论

重金属污染可归纳为 2 类, 一类是一些具有显 著生物毒性的重金属物，如镉 $(\mathrm{Cd})$ 、砷 $(\mathrm{As})$ 等，另一 类为超过一定量后具有生物毒性的一些重金属, 如 锌 $(\mathrm{Zn}) 、$ 铜 $(\mathrm{Cu})$ 等 $^{[33]}$ 。近年来, 土壤重金属污染越来 越引起人们关注 ${ }^{[34]}$ 。在土壤中过量的锌富积会抑制 植物生长，导致营养失衡、萎黄叶片，以及光合作用 受损 ${ }^{[5-6]}$ 。研究表明, 甘蓝型油菜对重金属锌具有较强 的耐受性，在较高浓度下仍可获得较高的生物产 量 ${ }^{[2-5]}$ 。然而关于油菜响应锌胁迫的分子机制尚未见 报道。在甘蓝型油菜中, 通过 GWAS 分析与基因组 信息相结合已成为挖掘油菜数量性状基因座的常 规手段, 并获得了一些与非生物胁迫相关的候选基

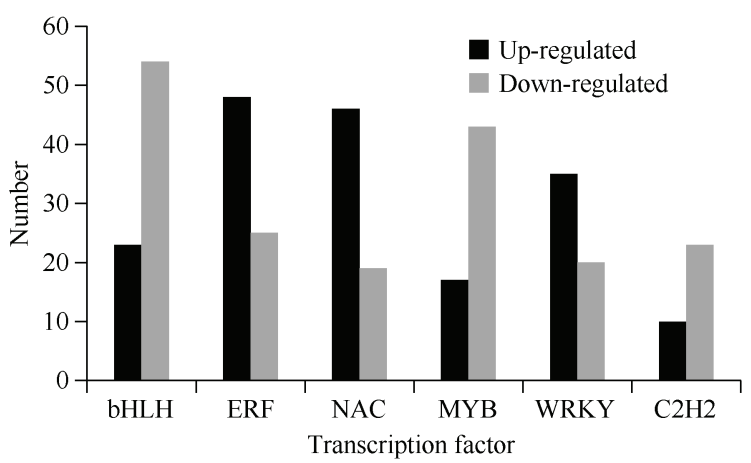

图 5 油菜锌胁迫后上调和下调转录因子基因数目

Fig. 5 Number of up-regulated and down-regulated transcription factors under zinc stress treatment in B. napus

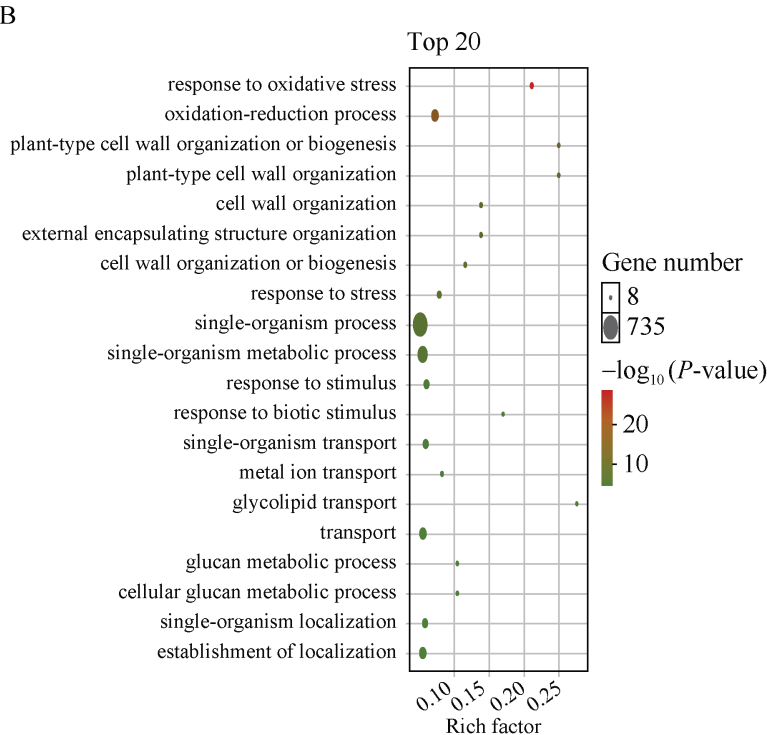

图 6 油菜锌胁迫后差异表达上调(A)和下调基因(B) GO 富集分析

Fig. 6 Differentially up-regulated (A) and down-regulated (B) genes by GO enrichment analysis under zinc stress treatment in $B$. napus 
表 4 甘蓝型油菜锌胁迫下相关性状候选基因

Table 4 Candidate genes of the traits correlated with zinc stress treatment in B. napus

\begin{tabular}{|c|c|c|c|c|}
\hline $\begin{array}{c}\text { 候选基因 } \\
\text { Candidate genes }\end{array}$ & $\begin{array}{c}\text { 物理位置 } \\
\text { Physical position }\end{array}$ & $\begin{array}{c}\text { 拟南芥同源基因 } \\
\text { Homologs in } \\
\text { Arabidopsis }\end{array}$ & $\begin{array}{c}\text { 基因注释 } \\
\text { Gene annotation }\end{array}$ & $\begin{array}{c}\text { 差异倍数 } \\
\log _{2} \text { (Fold } \\
\text { change) }\end{array}$ \\
\hline BnaA02g30040D & Chr.A02: 21813781-21815282 & AT5G48250 & $\begin{array}{l}\text { B-box 型锌指蛋白 } \\
\text { B-box type zinc finger protein with CCT domain }\end{array}$ & 2.18 \\
\hline BnaA02g30270D & Chr.A02: 21934212-21936672 & AT5G48560 & $\begin{array}{l}\text { bHLH 转录因子 } \\
\text { Basic helix-loop-helix (bHLH) DNA-binding protein }\end{array}$ & -6.62 \\
\hline BnaA07g27330D & ChrA07: 19877781-19879164 & $A T 1 G 68670$ & $\begin{array}{l}\text { MYB 转录因子 } \\
\text { MYB-like transcription factor family protein }\end{array}$ & 2.15 \\
\hline BnaA07g27340D & Chr.A07: 19884616-19887579 & $A T 1 G 68690$ & $\begin{array}{l}\text { 蛋白激酶家族 } \\
\text { Protein kinase superfamily protein }\end{array}$ & 4.55 \\
\hline BnaA07g27500D & Chr.A07: 19996402-19997781 & $A T 1 G 68850$ & $\begin{array}{l}\text { 过氧化物酶家族蛋白 } \\
\text { Peroxidase superfamily protein }\end{array}$ & -2.06 \\
\hline BnaA07g27840D & Chr.A07: 20196357-20198149 & AT1G69310 & $\begin{array}{l}\text { WRKY } 57 \text { 转录因子 } \\
\text { WRKY DNA-binding protein } 57\end{array}$ & 2.64 \\
\hline BnaA07g28000D & Chr.A07: 20266703-20267687 & $A T 1 G 69490$ & $\begin{array}{l}\text { NAC 转录因子 } \\
\text { NAC-like, activated by AP3/PI (NAP) }\end{array}$ & 2.01 \\
\hline BnaA07g31860D & Chr.A07: 22136736-22137327 & AT1G74930 & ERF 转录因子 ORA47 & 3.71 \\
\hline BnaA07g34210D & Chr.A07: 23311591-23312410 & $A T 1 G 78360$ & $\begin{array}{l}\text { 谷胱甘肽转移酶（GSTU21） } \\
\text { Glutathione S-transferase TAU } 21 \text { (GSTU21) }\end{array}$ & -3.13 \\
\hline BnaA07g35030D & Chr.A07: 23695006-23698790 & AT1G79610 & $\mathrm{Na}^{+} / \mathrm{H}^{+}$逆向转运蛋白 $\mathrm{Na}^{+} / \mathrm{H}^{+}$antiporter 6 (NHX6) & 2.29 \\
\hline BnaA07g35090D & Chr.A07: 23714116-23714860 & $A T 1 G 79680$ & $\begin{array}{l}\text { 类细胞壁相关激酶 WALL } \\
\text { ASSOCIATED KINASE (WAK)-LIKE } 10 \text { (WAKL10) }\end{array}$ & 6.52 \\
\hline BnaA07g35350D & Chr.A07: 23800896-23801571 & $A T 1 G 80730$ & $\begin{array}{l}\text { 锌指蛋白 } \\
\text { Zinc-finger protein } 1 \text { (ZFP1) }\end{array}$ & -7.08 \\
\hline BnaC04g06210D & Chr.C04: 4439046-4439940 & AT3G55090 & $\begin{array}{l}\mathrm{ABC} \text { 转运蛋白 } \\
\mathrm{ABC}-2 \text { type transporter family protein }\end{array}$ & 2.10 \\
\hline BnaC04g06300D & Chr.C04: 4503767-4505873 & AT2G39210 & $\begin{array}{l}\text { 主要协助转运蛋白超家族 } \\
\text { Major facilitator superfamily protein (MFS) }\end{array}$ & 3.11 \\
\hline BnaC06g38840D & Chr.C06: $36254140-36254958$ & $A T 1 G 78360$ & $\begin{array}{l}\text { 谷胱甘肽转移酶(GSTU21) } \\
\text { Glutathione S-transferase TAU } 21 \text { (GSTU21) }\end{array}$ & -4.29 \\
\hline BnaC06g38850D & Chr.C06: 36255467-36256984 & $A T 1 G 78360$ & $\begin{array}{l}\text { 谷胱甘肽转移酶(GSTU21) } \\
\text { Glutathione S-transferase TAU } 21 \text { (GSTU21) }\end{array}$ & -2.35 \\
\hline BnaC06g39970D & Chr.C06: $36849441-36853390$ & $A T 1 G 79610$ & $\mathrm{Na}^{+} / \mathrm{H}^{+}$逆向转运蛋白 $\mathrm{Na}^{+} / \mathrm{H}^{+}$antiporter 6 (NHX6) & 4.01 \\
\hline BnaC06g40020D & Chr.C06: 36867031-36869575 & AT1G69730 & $\begin{array}{l}\text { 细胞壁相关激酶蛋白 } \\
\text { Wall-associated kinase family protein }\end{array}$ & 4.43 \\
\hline BnaC06g40250D & Chr.C06: 36958965-36959628 & $A T 1 G 80730$ & $\begin{array}{l}\text { 锌指蛋白 } \\
\text { Zinc-finger protein } 1 \text { (ZFP1) }\end{array}$ & -2.49 \\
\hline
\end{tabular}

因 $^{[14-16,35-37]}$ 。因此, 本研究通过对锌胁迫下 140 份甘 蓝型油菜发芽期的相对下胚轴长进行了全基因组关 联分析，共检测到 8 个显著关联的 SNP 位点, A02、 $\mathrm{C} 04$ 和 C06 染色体上显著关联的 SNP 位点分别位于 22.0、4.4 和 $36.8 \mathrm{Mb}, \mathrm{A} 07$ 染色体上显著关联的 SNP 位点位于 $22.0 \mathrm{Mb}$ 和 $23.5 \mathrm{Mb}$ 。曲存民等 ${ }^{[16]}$ 将砷胁迫 下甘蓝型油菜的 RHL 定位在 A02: $19.2 \mathrm{Mb} 22.0 \mathrm{Mb}$ 、 A07: $19.2 \mathrm{Mb} \sim 22.5 \mathrm{Mb} 、 \mathrm{~A} 07: 23.1 \mathrm{Mb} \sim 23.5 \mathrm{Mb} 、 \mathrm{C} 04$ : $4.3 \mathrm{Mb} \sim 4.5 \mathrm{Mb}$ 和 $\mathrm{C} 06: 31.6 \mathrm{Mb} \sim 36.8 \mathrm{Mb}$, 与本研究 定位结果一致, 这些位点具有一因多效性, 可能在 不同重金属胁迫过程中都起着重要作用。
在植物中, 重金属可以引起许多代谢过程发生 变化, 这些变化主要是通过氧化还原反应引起的, 同 时造成抗氧化酶的活化、细胞膜通透性改变和离子的 置换等反应 ${ }^{[38]}$ 。本研究发现锌胁迫后, 上调的差异表 达基因主要富集在细胞膜, 参与氧化还原反应、离子 转运、防御反应和硫化合物转运。本研究结合全基因 组关联分析和转录组测序, 找到 19 个与锌胁迫相关 的候选基因, 包括转录因子/基因, 如 WRKY57、ORA47 和 BnaA07g28000D (NAC), WRKY57 可以通过清除活 性氧提高植物抗旱和抗盐能力 ${ }^{[39-40]}$; 植物受到伤害和 水分胁迫时, ORA47 可通过调控脱落酸和茉莉酸信号 
途径来提高抗性 ${ }^{[41]}$ 。本研究中 WRKY57 和 ORA47 在 锌胁迫后显著上调表达, 可能在锌胁迫过程中起着重 要作用, 但具体的调控机制还需进一步研究。

本研究还找到了 B-box 型和锌指蛋白 ZFP1, 锌指蛋白中的锌指结构可以结合锌离子形成稳定 的指状结构, 编码锌指蛋白的众多基因已经被证明 在生物和非生物胁迫过程中起着重要作用 ${ }^{[42-43]}$ 。 Sun 等 ${ }^{[44]}$ 研究表明, 菜豆 MTF 通过激活色氨酸生 物合成调控烟草耐镉性, 锌指基序是其重要的结合 金属反应的元件。拟南芥锌指蛋白 ZAT6 通过谷胱 甘肽途径提高镉抗性 ${ }^{[45]}$, 而锌指蛋白 ZAT11 负调 控拟南芥镍抗性 ${ }^{[46]}$ 。本研究找到的 B-box 型锌指蛋 白基因 BnaA02g $30040 D$ 在锌胁迫后表达量上调, 而 锌指蛋白 $Z F P 1$ 基因表达量下调，它们可能通过不同 的机制来响应胁迫。另外, 本研究找到 2 个编码 $\mathrm{Na}^{+} / \mathrm{H}^{+}$逆向转运蛋白的基因 NHX6 (BnaA07g35030D 和 BnaC06g39970D), 锌胁迫后其表达量上调, Yang 等 ${ }^{[47]}$ 研究表明, 浮萍 $N H X 1$ 基因通过减少 $\mathrm{Cd}^{2+}$ 流入和 增加 $\mathrm{Cd}^{2+}$ 外排提高重金属镉抗性。本研究中 NHX6 表 达上调, 可能增加了 $\mathrm{Zn}^{2+}$ 的外排, 从而提高锌抗性。

重金属处理下植物细胞产生活性氧造成细胞氧 化损伤, 为了抵抗活性氧对细胞的损伤, 植物会产 生抗氧化酶及非酶抗氧化剂清除自由基 ${ }^{[48]}$ 。锌处理 下小麦过氧化氢含量、过氧化物酶及过氧化氢酶活 性均显著提高, 增强了小麦对锌的耐受性 ${ }^{[49]}$ 。本研 究找到一些与氧化还原反应相关的基因，如编码过 氧化物酶家族蛋白和谷胱甘肽转移酶基因 GSTU21。 GST 可使 GSH 与内源电子化合物结合而产生脱毒 ${ }^{[50]}$, 重金属 $(\mathrm{Cu}$ 和 $\mathrm{Al})$ 胁迫下，拟南芥 $G S T$ 基因表达上 调，超表达水稻 GSTU30 基因提高了拟南芥重金属 耐性 ${ }^{[51-52]}$ 。但是本研究中, GSTU21 基因在锌胁迫后 表达量下调, 可能是由于锌处理植株后, 重金属造 成的氧化胁迫反应超过了油菜自身的协调能力, 抗 氧化能力受到明显抑制。

另外, 本研究还定位到一些编码 ABC 和 MSF 转运蛋白的基因, 其功能是将重金属转运到液泡内, 在重金属转运过程中起着重要作用 ${ }^{[53-54]}$, 这些转运 蛋白基因表达量上调, 可能通过相似的途径增强植 株对锌的抗性。拟南芥铝胁迫后, 可以诱导 WAK1 基因的表达 ${ }^{[55]} ; W A L K 4$ 基因启动子的突变导致水稻 对钾、钠、铜和锌超敏感, WALK4 突变导致水稻茎 中锌含量下降 ${ }^{[56]} ; W A K L 10$ 基因表达量上调, 其可能 在锌胁迫过程中起着重要作用。本研究为深入研究 甘蓝型油菜响应锌胁迫的分子机制奠定了基础。

\section{4 结论}

全基因组关联分析共鉴定出 8 个与锌胁迫显著 关联的 SNP 位点, 结合转录组测序结果, 共找到 19 个候选基因, 可能在锌胁迫过程中起着重要作用。

\section{References}

[1] Koeppe D E. The uptake, distribution, and effect of cadmium and lead in plants. Sci Total Environ, 1977, 7: 197-206.

[2] Sinclair S A, Kramer U. The zinc homeostasis network of land plants. Biochim Biophys Acta, 2012, 1823: 1553-1567.

[3] Emamverdian A, Ding Y, Mokhberdoran F, Xie Y. Heavy metal stress and some mechanisms of plant defense response. Sci World $J, 2015,2015: 756120$.

[4] Broadley M R, White P J, Hammond J P, Zelko I, Lux A. Zinc in plants. New Phytol, 2007, 173: 677-702.

[5] Cambrollé J, Mancilla-Leytón J M, Muñoz-Vallés S, Luque T, Figueroa M E. Zinc tolerance and accumulation in the salt-marsh shrub Halimione portulacoides. Chemosphere, 2012, 86: 867-874.

[6] 龚红梅, 李卫国. 锌对植物的毒害及机理研究进展. 安徽农业 科学, 2009, 37: 14009-14015.

Gong H M, Li W G. Research progress on the toxicity of zinc to plants and its mechanism. J Anhui Agric Sci, 2009, 37: 14009-14015 (in Chinese with English abstract).

[7] Belouchrani A S, Mameri N, Abdi N, Grib H, Lounici H, Drouiche N. Phytoremediation of soil contaminated with $\mathrm{Zn}$ using canola (Brassica napus L.). Ecol Eng, 2016, 95: 43-49.

[8] Gasic K, Korban S S. Expression of Arabidopsis phytochelatin synthase in Indian mustard (Brassica juncea) plants enhances tolerance for Cd and Zn. Planta, 2007, 225: 1277-1285.

[9] Cojocaru P, Gusiatin Z M, Cretescu I. Phytoextraction of Cd and $\mathrm{Zn}$ as single or mixed pollutants from soil by rape (Brassica napus). Environ Sci Pollut Res, 2016, 23: 10693-10701.

[10] Salt D E, Blaylock M, Kumar N, Dushenkov V, Ensley B D, Chet I, Raskin I. Phytoremediation: a novel strategy for the removal of toxic metals from the environment using plants. Biotechnol, 1995, 13: $468-474$.

[11] Turan M, Bringu A. Phytoremediation based on canola (Brassica napus L.) and Indian mustard (Brassica juncea L.) planted on spiked soil by aliquot amount of $\mathrm{Cd}, \mathrm{Cu}, \mathrm{Pb}$, and $\mathrm{Zn}$. Plant Soil Environ, 2007, 53: 7-15.

[12] 曹春信, 刘新华, 周琴, 江巧君, 袁名安, 江海东. 过量锌对 油菜生长、产量和养分吸收的影响及锌在植株地上部器官中 的富集特征. 浙江农业学报, 2011, 23: 781-791.

Cao C X, Liu X H, Zhou Q, Jiang Q J, Yuan M A, Jiang H D. Effects of excess zinc strss on growth yield nutrient uptake and enrichment characteristics of zinc in above-ground organs of rapeseed (Brassica napus). Acta Agric Zhejiangenisis, 2011, 23: 781-791 (in Chinese with English abstract).

[13] Zhang J, Chen K, Pang Y L, Naveed S A, Zhao X Q, Wang X Q, Wang Y, Dingkuhn M, Pasuquin J, Li Z K, Xu J L. QTL mapping and candidate gene analysis of ferrous iron and zinc toxicity tolerance at seedling stage in rice by genome-wide association 
study. BMC Genomics, 2017, 18: 828.

[14] Chen L L, Wan H P, Qian J L, Guo J B, Sun C M, Wen J, Yi B, Ma C Z, Tu J X, Song L Q, Fu T D, Shen J X. Genome-wide association study of cadmium accumulation at the seedling stage in rapeseed (Brassica napus L.). Front Plant Sci, 2018, 9: 375.

[15] Zhang F G, Xiao X, Yan G X, Hu J H, Cheng X, Li L X, Li H G, $\mathrm{Wu} X \mathrm{X}$. Association mapping of cadmium-tolerant QTLs in Brassica napus L. and insight into their contributions to phytoremediation. Environ Exp Bot, 2018, 155: 420-428.

[16] 曲存民, 马国强, 朱美晨, 黄小虎, 贾乐东, 王书贤, 赵会彦, 徐新福, 卢坤, 李加纳, 王瑞. 砷胁迫下甘蓝型油菜苗期根、 下胚轴和鲜重的全基因组关联分析. 作物学报, 2019，45: 175-187.

Qu C M, Ma G Q, Zhu M C, Huang X H, Jia L D, Wang S X, Zhao H Y, Xu X F, Lu K, Li J N, Wang R. Genome-wide association of roots, hypocotyls and fresh weight at germination stage as stress in Brassica napus L. Acta Agron Sin, 2019, 45: 175-187 (in Chinese with English abstract).

[17] Xu J, Chai T Y, Zhang Y X, Lang M L, Han L. The cation-efflux transporter BjCET2 mediates zinc and cadmium accumulation in Brassica juncea L. leaves. Plant Cell Rep, 2009, 28: 1235-1242.

[18] Song Y, Hudek L, Freestone D, Puhui J, Michalczyk A A, Senlin Z, Ackland M L. Comparative analyses of cadmium and zinc uptake correlated with changes in natural resistance-associated macrophage protein (NRAMP) expression in Solanum nigrum L. and Brassica rapa. Environ Chem, 2014, 11: 653-660.

[19] Lichten L A, Cousins R J. Mammalian zinc transporters: nutritional and physiologic regulation. Anпи Rev Nutr, 2009, 29: 153-176.

[20] Li N N, Xiao H, Sun J J, Wang S F, Wang J C, Chang P, Zhou X B, Lei B, Lu K, Luo F, Shi X J, Li J N. Genome-wide analysis and expression profiling of the HMA gene family in Brassica napus under Cd stress. Plant Soil, 2018, 426: 365-381.

[21] Wang J W, Li Y, Zhang Y X, Chai T Y. Molecular cloning and characterization of a Brassica juncea yellow stripe-like gene, BjYSL7, whose overexpression increases heavy metal tolerance of tobacco. Plant Cell Rep, 2013, 32: 651-662.

[22] Takahashi R, Bashir K, Ishimaru Y, Nishizawa N K, Nakanishi H. The role of heavy-metal ATPases, HMAs, in zinc and cadmium transport in rice. Plant Signal Behav, 2012, 7: 1605-1607.

[23] 张苾, 邓文亚, 杨柳, 王亚萍, 肖芳枝, 禾健, 卢坤. 盐胁迫下 甘蓝型油菜发芽期下胚轴和根长的全基因组关联分析. 中国 农业科学, 2017, 50: 15-35.

Zhang R, Deng W Y, Yang L, Wang Y P, Xiao F Z, He J, Lu K. Genome-wide association study of root length and hypocotyl length at germination stage under saline conditions in Brassica napus. Sci Agric Sin, 2017, 50: 15-35 (in Chinese with English abstract).

[24] Munns R, James R A. Screening methods for salinity tolerance: a case study with tetraploid wheat. Plant Soil, 2003, 253: 201-218.

[25] Qu C M, Li M, Duan X J, Fan J H, Jia L D, Zhao H Y, Lu K, Li J $\mathrm{N}, \mathrm{Xu}$ X F, Wang R. Identification of candidate genes for seed glucosinolate content using association mapping in Brassica napus L. Genes, 2015, 6: 1215-1229.

[26] 卢坤, 王腾岳, 徐新福, 唐章林, 曲存民, 贺斌, 梁颖, 李加纳. 甘蓝型油菜结角高度与荚层厚度的全基因组关联分析. 作物
学报, 2016, 42: 344-352.

Lu K, Wang T Y, Xu X F, Tang Z L, Qu C M, He B, Liang Y, Li J $\mathrm{N}$. Genome-wide association analysis of height of podding and thickness of pod canopy in Brassica napus. Acta Agron Sin, 2016, 42: 344-352 (in Chinese with English abstract).

[27] Pritchard J K, Stephens M, Donnelly P. Inference of population structure using multilocus genotype data. Genetics, 2000, 155: 945-959.

[28] Evanno G, Regnaut S, Goudet J. Detecting the number of clusters of individuals using the software structure: a simulation study. Mol Ecol, 2005, 14: 2611-2620.

[29] Hardy O J, Vekemans X. Spagedi: a versatile computer program to analyse spatial genetic structure at the individual or population levels. Mol Ecol Notes, 2002, 2: 618-620.

[30] Bradbury P J, Zhang Z, Kroon D E, Casstevens T M, Ramdoss Y, Buckler E S. TASSEL: software for association mapping of complex traits in diverse samples. Bioinformatics, 2007, 23: 2633-2635.

[31] Wen Y J, Zhang H W, Ni Y L, Huang B, Zhang J, Feng J Y, Wang S B, Dunwell J M, Zhang Y M, Wu R L. Methodological implementation of mixed linear models in multi-locus genome-wide association studies. Brief Bioinform, 2018, 19: 700-712.

[32] Chalhoub B, Denoeud F, Liu S, Parkin I A P, Tang H, Wang X, Chiquet J, Belcram H, Tong C, Samans B, Corréa M, Da Silva C, Just J, Falentin C, Koh C S, Le Clainche I, Bernard M, Bento P, Noel B, Labadie K, Alberti A, Charles M, Arnaud D, Guo H, Daviaud C, Alamery S, Jabbari K, Zhao M, Edger P P, Chelaifa H, Tack D, Lassalle G, Mestiri I, Schnel N, Le Paslier M C, Fan G, Renault V, Bayer P E, Golicz A A, Manoli S, Lee T, Thi V, Chalabi S, Hu Q, Fan C, Tollenaere R, Lu Y, Battail C, Shen J, Sidebottom C H D, Wang X, Canaguier A, Chauveau A, Bérard A, Deniot G, Guan M, Liu Z, Sun F, Lim Y P, Lyons E, Town C D, Bancroft I, Wang X, Meng J, Ma J, Pires J C, King G J, Brunel D, Delourme R, Renard M, Aury J, Adams K L, Batley J, Snowdon R J, Tost J, Edwards D, Zhou Y, Hua W, Sharpe A G, Paterson A $\mathrm{H}$, Guan C, Wincker P. Early allopolyploid evolution in the post-Neolithic Brassica napus oilseed genome. Science, 2014, 345: 950-953.

[33] 郑喜珅, 鲁安怀, 高翔, 赵谨, 郑德圣. 土壤中重金属污染现 状与防治方法. 土壤与环境, 2002, 11(1): 79-84.

Zheng X K, Lu A H, Gao X, Zhao J, Zheng D S. Contamination of heavy metals in soil present situation and method. Soil Environ Sci, 2002, 11(1): 79-84 (in Chinese with English abstract).

[34] Zhong B, Liang T, Wang L, Li K. Applications of stochastic models and geostatistical analyses to study sources and spatial patterns of soil heavy metals in a metalliferous industrial district of China. Sci Total Environ, 2014, 490: 422-434.

[35] Zhang F, Xiao X, Xu K, Cheng X, Xie T, Hu J, Wu X. Genome-wide association study (GWAS) reveals genetic loci of lead $(\mathrm{Pb})$ tolerance during seedling establishment in rapeseed (Brassica napus L.). BMC Genomics, 2020, 21: 139.

[36] Zhang J, Mason A S, Wu J, Liu S, Zhang X, Luo T, Redden R, Batley J, Hu L, Yan G. Identification of putative candidate genes for water stress tolerance in canola (Brassica napus). Front Plant Sci, 2015, 6: 1058.

[37] Ke L, Lei W, Yang W, Wang J, Gao J, Cheng J, Sun Y, Fan Z, Yu 
D. Genome-wide identification of cold responsive transcription factors in Brassica napus L. BMC Plant Biol, 2020, 20: 62.

[38] Shahid M, Natasha, Khalid S, Abbas G, Niazi N K, Murtaza B, Rashid M I, Bibi I. Redox mechanisms and plant tolerance under heavy metal stress: genes and regulatory networks. In: Sablok G, eds. Plant Metallomics and Functional Omics. Cham: Springer, 2019. pp 71-105.

[39] Jiang Y, Qiu Y, Hu Y, Yu D. Heterologous expression of AtWRKY57 confers drought tolerance in Oryza sativa. Front Plant Sci, 2016, 7: 145.

[40] Jiang Y, Liang G, Yu D. Activated expression of WRKY57 confers drought tolerance in Arabidopsis. Mol Plant, 2012, 5: 1375-1388.

[41] Chen H Y, Hsieh E J, Cheng M C, Chen C Y, Hwang S Y, Lin T P. ORA47 (octadecanoid-responsive AP2/ERF-domain transcription factor 47) regulates jasmonic acid and abscisic acid biosynthesis and signaling through binding to a novel cis-element. New Phytol, 2016, 211: 599-613.

[42] Zang D D, Li H Y, Xu H Y, Zhang W H, Zhang Y M, Shi X X, Wang Y C. An arabidopsis zinc finger protein increases abiotic stress tolerance by regulating sodium and potassium homeostasis, reactive oxygen species scavenging and osmotic potential. Front Plant Sci, 2016, 7: 1272.

[43] Cao H J, Huang P Y, Zhang L L, Shi Y K, Sun D D, Yan Y X, Liu X H, Dong B, Chen G Q, Snyder J H, Lin F C, Lu J P. Characterization of $47 \mathrm{Cys}_{2}-\mathrm{His}_{2}$ zinc finger proteins required for the development and pathogenicity of the rice blast fungus Magnaporthe oryzae. New Phytol, 2016, 211: 1035-1051.

[44] Sun N, Liu M, Zhang W, Yang W, Bei X, Ma H, Qiao F, Qi X. Bean metal-responsive element-binding transcription factor confers cadmium resistance in tobacco. Plant Physiol, 2015, 167: $1136-1148$.

[45] Chen J, Yang L, Yan X, Liu Y, Wang R, Fan T, Ren Y, Tang X, Xiao F, Liu Y, Cao S. Zinc-finger transcription factor ZAT6 positively regulates cadmium tolerance through the glutathionedependent pathway in Arabidopsis. Plant Physiol, 2016, 171: 707-719.

[46] Liu X M, An J, Han H J, Kim S H, Lim C O, Yun D J, Chung W S. ZAT11, a zinc finger transcription factor, is a negative regulator of nickel ion tolerance in Arabidopsis. Plant Cell Rep, 2014, 33: 2015-2021.
[47] Yang L, Wei Y, Na L, Zeng J Y, Han Y J, Zuo Z J, Wang S T, Zhu Y R, Zhang Y, Sun J S, Yong W. Declined cadmium accumulation in $\mathrm{Na}^{+} / \mathrm{H}^{+}$antiporter (NHX1) transgenic duckweed under cadmium stress. Ecotoxicol Environ Saf, 2019, 182: 109397.

[48] 李洋, 于丽杰, 金晓霞. 植物重金属胁迫耐受机制. 中国生物 工程杂志, 2015, 35(9): 94-104.

Li Y, Yu L J, Jin X X. The mechanism of heavy metal stress in plants. China Biotechnol, 2015, 35(9): 94-104 (in Chinese with English abstract).

[49] 李小宁. 锌胁迫对小麦种子萌发及幼苗生理生化特性的影响. 西北师范大学硕士毕业论文, 甘肃兰州, 2013.

Li X N. Effects of Zinc Stress on Seed Germination, Physiological and Biochemical Characteristics in Wheat Seedling. MS Thesis of Northwest Normal University, Lanzhou, Gansu, China, 2013 (in Chinese with English abstract).

[50] Kumar S, Trivedi P K. Glutathione S-transferases: role in combating abiotic stresses including arsenic detoxification in plants. Front Plant Sci, 2018, 9: 751.

[51] Ezaki B, Gardner R C, Ezaki Y, Matsumoto H. Expression of aluminum-induced genes in transgenic Arabidopsis plants can ameliorate aluminum stress and/or oxidative stress. Plant Physiol, 2000, 122: 657-665.

[52] Srivastava D, Verma G, Chauhan A S, Pande V, Chakrabarty D. Rice (Oryza sativa L.) tau class glutathione S-transferase (OsGSTU30) overexpression in Arabidopsis thaliana modulates a regulatory network leading to heavy metal and drought stress tolerance. Metallomics, 2019, 11: 375-389.

[53] Zhang J, Martinoia E, Lee Y. Vacuolar transporters for cadmium and arsenic in plants and their applications in phytoremediation and crop development. Plant Cell Physiol, 2018, 59: 1317-1325.

[54] Kim D Y, Bovet L, Maeshima M, Martinoia E, Lee Y. The ABC transporter AtPDR8 is a cadmium extrusion pump conferring heavy metal resistance. Plant $J, 2007$, 50: 207-218.

[55] Korenkov V, King B, Hirschi K, Wagner G J. Root-selective expression of AtCAX4 and AtCAX2 results in reduced lamina cadmium in field-grown Nicotiana tabacum L. Plant Biotechnol J, 2009, 7: 219-226.

[56] Hou X W, Tong H Y, Selby J, DeWitt J, Peng X X, He Z H. Involvement of a cell wall-associated kinase, WAKL4, in Arabidopsis mineral responses. Plant Physiol, 2005, 139: 1704-1716.

附表 1140 份甘蓝型油菜材料信息

Table S1 Detailed information of the 140 B. napus accessions

\begin{tabular}{clll}
\hline $\begin{array}{c}\text { 编号 } \\
\text { Number }\end{array}$ & \multicolumn{1}{c}{$\begin{array}{c}\text { 材料名称 } \\
\text { Accessions }\end{array}$} & \multicolumn{1}{c}{$\begin{array}{c}\text { 生态型 } \\
\text { Ecotype }\end{array}$} & $\begin{array}{c}\text { 来源 } \\
\text { Source }\end{array}$ \\
\hline 1 & 中双 3 号 Zhongshuang 3 & 半冬性 Semi-winter & 中国浙江 Zhejiang, China \\
中国江苏 Jiangsu, China \\
半冬性 Semi-winter & 中国重庆 Chongqing, China \\
3 & 镇油 5 号 Zhenyou 5 & 半冬性 Semi-winter & 中国湖北 Hubei, China \\
4 & SWU46 & 半冬性 Semi-winter & 中国湖北 Hubei, China \\
5 & WH-127 & 半冬性 Semi-winter & 中国湖南 Hunan, China \\
6 & WX10329 & 半冬性 Semi-winter & 中国湖北 Hubei, China \\
7 & JY-16 & 半冬性 Semi-winter & 中国贵州 Guizhou, China \\
\hline 8 & 黔油 331 Qianyou 331 & 半冬性 Semi-winter &
\end{tabular}




\begin{tabular}{|c|c|c|c|}
\hline $\begin{array}{c}\text { 编号 } \\
\text { Number }\end{array}$ & $\begin{array}{l}\text { 材料名称 } \\
\text { Accessions }\end{array}$ & $\begin{array}{l}\text { 生态型 } \\
\text { Ecotvpe }\end{array}$ & 来源 \\
\hline 9 & SWU47 & 半冬性 Semi-winter & 中国重庆 Chongqing, China \\
\hline 10 & 浙双 72 Zheshuang 72 & 半冬性 Semi-winter & 中国浙江 Zhejiang, China \\
\hline 11 & 沪油 17 Huyou 17 & 半冬性 Semi-winter & 中国上海 Shanghai, China \\
\hline 12 & 中双 7 号 Zhongshuang 7 & 半冬性 Semi-winter & 中国武汉 Wuhan, China \\
\hline 13 & WH-26 & 半冬性 Semi-winter & 中国湖北 Hubei, China \\
\hline 14 & Taisetsu & 冬性 Winter & 日本 Japan \\
\hline 15 & M114 & 半冬性 Semi-winter & 中国 China \\
\hline 16 & 中油 589 Zhongyou 589 & 半冬性 Semi-winter & 中国武汉 Wuhan, China \\
\hline 17 & 农林 43 Nonglin 43 & 冬性 Winter & 日本 Japan \\
\hline 18 & 广德 8104 Guangde 8104 & 半冬性 Semi-winter & 中国江苏 Jiangsu, China \\
\hline 19 & 至尊 Zhizun & 半冬性 Semi-winter & 中国湖北 Hubei, China \\
\hline 20 & 中双 2 号 Zhongshuang 2 & 半冬性 Semi-winter & 中国湖北 Hubei, China \\
\hline 21 & 中双 4 号 Zhongshuang 4 & 半冬性 Semi-winter & 中国湖北 Hubei, China \\
\hline 22 & 华油 3 号 Huayou 3 & 半冬性 Semi-winter & 中国湖北 Hubei, China \\
\hline 23 & 宁油 14 Ningyou 14 & 半冬性 Semi-winter & 中国江苏 Jiangsu, China \\
\hline 24 & 华油 12 Huayou 12 & 半冬性 Semi-winter & 中国湖北 Hubei, China \\
\hline 25 & 湖北白花油菜 Hubei white flower rape & 半冬性 Semi-winter & 中国湖北 Hubei, China \\
\hline 26 & WH-58 & 半冬性 Semi-winter & 中国湖北 Hubei, China \\
\hline 27 & 699 & 半冬性 Semi-winter & 中国湖北 Hubei, China \\
\hline 28 & SWU63 & 半冬性 Semi-winter & 中国重庆 Chongqing, China \\
\hline 29 & WH-57 & 半冬性 Semi-winter & 中国湖北 Hubei, China \\
\hline 30 & 苏油 1 号 Shuyou 1 & 半冬性 Semi-winter & 中国江苏 Jiangsu, China \\
\hline 31 & WH-19 & 半冬性 Semi-winter & 中国湖北 Hubei, China \\
\hline 32 & 中双 4 号 Zhongshuang 4 & 半冬性 Semi-winter & 中国湖北 Hubei, China \\
\hline 33 & Nakate Chousen & 春性 Spring & 朝鲜 DPRK \\
\hline 34 & 广德 761 Gaungde 761 & 半冬性 Semi-winter & 中国江苏 Jiangsu, China \\
\hline 35 & SWU110 & 半冬性 Semi-winter & 中国重庆 Chongqing, China \\
\hline 36 & 7094 & 半冬性 Semi-winter & 中国湖北 Hubei, China \\
\hline 37 & SWU71 & 半冬性 Semi-winter & 中国重庆 Chongqing, China \\
\hline 38 & 1111 & 半冬性 Semi-winter & 中国湖北 Hubei, China \\
\hline 39 & Erake & 半冬性 Semi-winter & 波兰 Poland \\
\hline 40 & Campino & 春性 Spring & 德国 Germany \\
\hline 41 & 宁油 10 号 Ningyou 10 & 半冬性 Semi-winter & 中国江苏 Jiangsu, China \\
\hline 42 & 中双 11DH Zhongshuang 11DH & 半冬性 Semi-winter & 中国湖北 Hubei, China \\
\hline 43 & 浙双 8 号 Zheshuang 8 & 半冬性 Semi-winter & 中国浙江 Zhejiang, China \\
\hline 44 & cresor & 春性 Spring & 法国 France \\
\hline 45 & 浙油 17 Zheyou 17 & 半冬性 Semi-winter & 中国浙江 Zhejiang, China \\
\hline 46 & 华航 901 Huahang 901 & 半冬性 Semi-winter & 中国湖北 Hubei, China \\
\hline 47 & Wesreo & 春性 Spring & 澳大利亚 Australia \\
\hline 48 & 南川长角 Nanchuansiliqua & 半冬性 Semi-winter & 中国重庆 Chongqing, China \\
\hline 49 & $\mathrm{~J}-917$ & 半冬性 Semi-winter & 中国湖北 Hubei, China \\
\hline 50 & 浙双 6 号 Zheshuang 6 & 半冬性 Semi-winter & 中国浙江 Zhejiang, China \\
\hline 51 & 荣选 Rongxuan & 半冬性 Semi-winter & 中国江苏 Jiangsu, China \\
\hline 52 & SWU106 & 半冬性 Semi-winter & 中国重庆 Chongqing, China \\
\hline
\end{tabular}


(续附表 1)

\begin{tabular}{|c|c|c|c|}
\hline $\begin{array}{c}\text { 编号 } \\
\text { Number }\end{array}$ & $\begin{array}{l}\text { 材料名称 } \\
\text { Accessions }\end{array}$ & $\begin{array}{l}\text { 生态型 } \\
\text { Ecotype }\end{array}$ & $\begin{array}{c}\text { 来源 } \\
\text { Source }\end{array}$ \\
\hline 53 & D2 & 春性 Spring & 丹麦 Denmark \\
\hline 54 & 豫油 1 号 Yuyou 1 & 半冬性 Semi-winter & 中国重庆 Chongqing, China \\
\hline 55 & WH-37 & 半冬性 Semi-winter & 中国湖北 Hubei, China \\
\hline 56 & $\mathrm{~J}-951$ & 半冬性 Semi-winter & 中国湖北 Hubei, China \\
\hline 57 & 全紫油菜 Quanzi rape & 春性 Spring & 中国江苏 Jiangsu, China \\
\hline 58 & SWU69 & 半冬性 Semi-winter & 中国重庆 Chongqing, China \\
\hline 59 & SWU60 & 半冬性 Semi-winter & 中国重庆 Chongqing, China \\
\hline 60 & 丰油 9 号 Fengyou 9 & 半冬性 Semi-winter & 中国河南 Henan, China \\
\hline 61 & 宁油 1 号 Ningyou 1 & 半冬性 Semi-winter & 中国湖北 Hubei, China \\
\hline 62 & SWU80 & 半冬性 Semi-winter & 中国重庆 Chongqing, China \\
\hline 63 & $10-\mathrm{C} 29$ & 半冬性 Semi-winter & 中国湖北 Hubei, China \\
\hline 64 & 秦油 5 号 Qinyou 5 & 半冬性 Semi-winter & 中国陕西 Shaanxi, China \\
\hline 65 & Sophia & 春性 Spring & 德国 Germany \\
\hline 66 & WaseChousen & 春性 Spring & 朝鲜 DPRK \\
\hline 67 & Korina & 春性 Spring & 德国 Germany \\
\hline 68 & $\mathrm{~J}-915$ & 半冬性 Semi-winter & 中国湖北 Hubei, China \\
\hline 69 & Bienvenu & 半冬性 Semi-winter & 法国 France \\
\hline 70 & SWU102 & 半冬性 Semi-winter & 中国重庆 Chongqing, China \\
\hline 71 & 漕泾胜利 Caojingshengli & 半冬性 Semi-winter & 中国上海 Shanghai, China \\
\hline 72 & 563 & 半冬性 Semi-winter & 中国湖南 Hunan, China \\
\hline 73 & 皖油 15 号 Wanyou 15 & 半冬性 Semi-winter & 中国安徽 Anhui, China \\
\hline 74 & 阳光 198 Yangguang 198 & 半冬性 Semi-winter & 中国湖北 Hubei, China \\
\hline 75 & 湘油 13 号 Xiangyou 13 & 半冬性 Semi-winter & 中国湖南 Hunan, China \\
\hline 76 & 皖油 16 号 Wanyou 16 & 半冬性 Semi-winter & 中国安徽 Anhui, China \\
\hline 77 & 华油 13 号 Huayou 13 & 半冬性 Semi-winter & 中国湖北 Hubei, China \\
\hline 78 & 湘油 15 号 Xiangyou 15 & 半冬性 Semi-winter & 中国湖南 Hunan, China \\
\hline 79 & Tapidor & 冬性 Winter & 法国 France \\
\hline 80 & $10-\mathrm{C} 24$ & 半冬性 Semi-winter & 中国湖北 Hubei, China \\
\hline 81 & 圣光 77 Shengguang 77 & 半冬性 Semi-winter & 中国湖北 Hubei, China \\
\hline 82 & 史力丰 Shilifeng & 半冬性 Semi-winter & 中国江苏 Jiangsu, China \\
\hline 83 & 沪油 3 号 Huyou 3 & 半冬性 Semi-winter & 中国上海 Shanghai, China \\
\hline 84 & Santana & 半冬性 Semi-winter & 中国 China \\
\hline 85 & $10-\mathrm{C} 34$ & 半冬性 Semi-winter & 中国湖北 Hubei, China \\
\hline 86 & $11-Y 7-117$ & 半冬性 Semi-winter & 中国湖北 Hubei, China \\
\hline 87 & SWU99 & 半冬性 Semi-winter & 中国重庆 Chongqing, China \\
\hline 88 & 宁油 12 Ningyou 12 & 半冬性 Semi-winter & 中国江苏 Jiangsu, China \\
\hline 89 & Comet & 春性 Spring & 瑞典 Sweden \\
\hline 90 & WH-20 & 半冬性 Semi-winter & 中国湖北 Hubei, China \\
\hline 91 & 扬 J6711 Yang J6711 & 半冬性 Semi-winter & 中国江苏 Jiangsu, China \\
\hline 92 & 7191 & 半冬性 Semi-winter & 中国湖北 Hubei, China \\
\hline 93 & 中双 9 号 Zhongshuang 9 & 半冬性 Semi-winter & 中国湖北 Hubei, China \\
\hline 94 & Daechosen & 半冬性 Semi-winter & 朝鲜 DPRK \\
\hline 95 & Monty & 半冬性 Semi-winter & 澳大利亚 Australia \\
\hline 96 & 纬隆 88 Weilong 88 & 半冬性 Semi-winter & 中国陕西 Shanxi, China \\
\hline
\end{tabular}


(续附表 1)

\begin{tabular}{|c|c|c|c|}
\hline 编号 & 材料名称 & 生态型 & 来源 \\
\hline Number & Accessions & Ecotype & Source \\
\hline 97 & 沪油 14 Huyou 14 & 半冬性 Semi-winter & 中国上海 Shanghai, China \\
\hline 98 & A117 & 半冬性 Semi-winter & 中国陕西 Shaanxi, China \\
\hline 99 & WH-15 & 半冬性 Semi-winter & 中国湖北 Hubei, China \\
\hline 100 & 2011-7103 & 半冬性 Semi-winter & 中国湖北 Hubei, China \\
\hline 101 & SWU68 & 半冬性 Semi-winter & 中国重庆 Chongqing, China \\
\hline 102 & 浙油 18 Zheyou 18 & 半冬性 Semi-winter & 中国四川 Zhejiang, China \\
\hline 103 & Yan $81-2$ & 半冬性 Semi-winter & 中国重庆 Chongqing, China \\
\hline 104 & 2012-K8053 & 半冬性 Semi-winter & 中国湖北 Hubei, China \\
\hline 105 & 淮油 6 号 Huaiyou 6 & 半冬性 Semi-winter & 中国江苏 Jiangsu, China \\
\hline 106 & $2012-3546$ & 半冬性 Semi-winter & 中国湖北 Hubei, China \\
\hline 107 & wx 10296 & 半冬性 Semi-winter & 中国湖南 Hunan, China \\
\hline 108 & $2012-8380$ & 半冬性 Semi-winter & 中国湖北 Hubei, China \\
\hline 109 & SWU92 & 半冬性 Semi-winter & 中国重庆 Chongqing, China \\
\hline 110 & 农林 42 Nonglin 42 & 半冬性 Semi-winter & 日本 Japan \\
\hline 111 & 大花球 Dahuaqiu & 半冬性 Semi-winter & 中国江苏 Jiangsu, China \\
\hline 112 & 华油 6 号 Huayou 6 & 半冬性 Semi-winter & 中国湖北 Hubei, China \\
\hline 113 & CY12Q95406 & 半冬性 Semi-winter & 中国四川 Sichuan, China \\
\hline 114 & SWU49 & 半冬性 Semi-winter & 中国重庆 Chongqing, China \\
\hline 115 & SWU70 & 半冬性 Semi-winter & 中国重庆 Chongqing, China \\
\hline 116 & 华双 128 Huashuang 128 & 半冬性 Semi-winter & 中国湖北 Hubei, China \\
\hline 117 & 皖油早 Wanyouzao & 半冬性 Semi-winter & 中国安徽 Anhui, China \\
\hline 118 & 宁油 12 Ningyou 12 & 半冬性 Semi-winter & 中国江苏 Jiangsu, China \\
\hline 119 & 滁油 1 号 Chuyou 1 & 半冬性 Semi-winter & 中国安徽 Anhui, China \\
\hline 120 & 10-JP3 & 半冬性 Semi-winter & 中国湖北 Hubei, China \\
\hline 121 & 2359 & 半冬性 Semi-winter & 中国湖北 Hubei, China \\
\hline 122 & 宁油 8 号 Ningyou 8 & 半冬性 Semi-winter & 中国江苏 Jiangsu, China \\
\hline 123 & CY21PXW-84 & 半冬性 Semi-winter & 中国四川 Sichuan, China \\
\hline 124 & SWU88 & 半冬性 Semi-winter & 中国重庆 Chongqing, China \\
\hline 125 & Sida & 春性 Spring & 加拿大 Canada \\
\hline 126 & 川油 20 Chuanyou 20 & 半冬性 Semi-winter & 中国四川 Sichuan, China \\
\hline 127 & 沪油 19 Huyou 19 & 半冬性 Semi-winter & 中国上海 Shanghai, China \\
\hline 128 & WH-62 & 半冬性 Semi-winter & 中国湖北 Hubei, China \\
\hline 129 & 华油 14 Huayou 14 & 半冬性 Semi-winter & 中国湖北 Hubei, China \\
\hline 130 & CY12GJ-1 & 半冬性 Semi-winter & 中国四川 Sichuan, China \\
\hline 131 & 湘油 11 号 Xiangyou 11 & 半冬性 Semi-winter & 中国湖南 Hunan, China \\
\hline 132 & 浙油 601 Zheyou 601 & 半冬性 Semi-winter & 中国浙江 Zhejiang, China \\
\hline 133 & SWU108 & 半冬性 Semi-winter & 中国重庆 Chongqing, China \\
\hline 134 & CY14PXW-18 & 半冬性 Semi-winter & 中国四川 Sichuan, China \\
\hline 135 & Nca & 半冬性 Semi-winter & 中国湖北 Hubei, China \\
\hline 136 & 甘油 5 号 Ganyou 5 & 半冬性 Semi-winter & 中国湖北 Hubei, China \\
\hline 137 & SWU94 & 半冬性 Semi-winter & 中国重庆 Chongqing, China \\
\hline 138 & 中油 821 Zhongyou 821 & 半冬性 Semi-winter & 中国湖北 Hubei, China \\
\hline 139 & 川油 18 Chuanyou 18 & 半冬性 Semi-winter & 中国四川 Sichuan, China \\
\hline 140 & wx 10213 & 半冬性 Semi-winter & 中国湖北 Hunan, China \\
\hline
\end{tabular}

